\title{
Effectiveness of a low intensity outpatient cognitive rehabilitation programme for patients in the chronic phase after acquired brain injury
}

Citation for published version (APA):

Rasquin, S. M. C., Bouwens, S. F. M., Dijcks, B., Winkens, I., Bakx, W. G. M., \& van Heugten, C. M. (2010). Effectiveness of a low intensity outpatient cognitive rehabilitation programme for patients in the chronic phase after acquired brain injury. Neuropsychological Rehabilitation, 20(5), 760-777. https://doi.org/10.1080/09602011.2010.484645

Document status and date:

Published: 01/01/2010

DOI:

10.1080/09602011.2010.484645

Document Version:

Publisher's PDF, also known as Version of record

Document license:

Taverne

Please check the document version of this publication:

- A submitted manuscript is the version of the article upon submission and before peer-review. There can be important differences between the submitted version and the official published version of record.

People interested in the research are advised to contact the author for the final version of the publication, or visit the DOI to the publisher's website.

- The final author version and the galley proof are versions of the publication after peer review.

- The final published version features the final layout of the paper including the volume, issue and page numbers.

Link to publication

\footnotetext{
General rights rights.

- You may freely distribute the URL identifying the publication in the public portal. please follow below link for the End User Agreement:

www.umlib.nl/taverne-license

Take down policy

If you believe that this document breaches copyright please contact us at:

repository@maastrichtuniversity.nl

providing details and we will investigate your claim.
}

Copyright and moral rights for the publications made accessible in the public portal are retained by the authors and/or other copyright owners and it is a condition of accessing publications that users recognise and abide by the legal requirements associated with these

- Users may download and print one copy of any publication from the public portal for the purpose of private study or research.

- You may not further distribute the material or use it for any profit-making activity or commercial gain

If the publication is distributed under the terms of Article $25 \mathrm{fa}$ of the Dutch Copyright Act, indicated by the "Taverne" license above, 


\title{
Neuropsychological Rehabilitation
}

\section{Effectiveness of a low intensity outpatient cognitive rehabilitation programme for patients in the chronic phase after acquired brain injury}

\author{
S. M. C. Rasquin , S. F. M. Bouwens , B. Dijcks , I. Winkens , W. G. M. Bakx \& C. \\ M. van Heugten
}

To cite this article: S. M. C. Rasquin , S. F. M. Bouwens, B. Dijcks , I. Winkens , W. G. M. Bakx \& C. M. van Heugten (2010) Effectiveness of a low intensity outpatient cognitive rehabilitation programme for patients in the chronic phase after acquired brain injury, Neuropsychological Rehabilitation, 20:5, 760-777, DOI: 10.1080/09602011.2010.484645

To link to this article: https://doi.org/10.1080/09602011.2010.484645

\section{曲 Published online: 09 Jun 2010.}

Submit your article to this journal

Џ Article views: 600

Q View related articles $\sqsubset$

4 Citing articles: 7 View citing articles ๘ 


\title{
Effectiveness of a low intensity outpatient cognitive rehabilitation programme for patients in the chronic phase after acquired brain injury
}

\author{
S. M. C. Rasquin ${ }^{1,2}$, S. F. M. Bouwens ${ }^{2}$, B. Dijcks ${ }^{3}$, I. Winkens ${ }^{2,3}$, \\ W. G. M. Bakx ${ }^{1}$, and C. M. van Heugten ${ }^{2,4,5}$ \\ ${ }^{1}$ Adelante Rehabilitation, Hoensbroek, The Netherlands; ${ }^{2}$ School for Mental \\ Health and Neuroscience, Department of Psychiatry and Neuropsychology, \\ Maastricht University, Maastricht, The Netherlands; ${ }^{3}$ Vilans, Utrecht, The \\ Netherlands; ${ }^{4}$ Centre of Excellence in Rehabilitation Medicine and Rudolf \\ Magnus Institute for Neurosciences, Utrecht, The Netherlands; ${ }^{5}$ Department of \\ Neuropsychology and Psychopharmacology, Faculty of Psychology and \\ Neuroscience, Maastricht University, Maastricht, The Netherlands
}

The aim of this prospective cohort study was to examine the effectiveness of a low intensity outpatient cognitive rehabilitation programme for patients with acquired brain injury in the chronic phase. Twenty-seven patients with acquired brain injury (i.e., stroke, traumatic brain injury, subarachnoid haemorrhage; $52 \%$ male) with a mean age of $49.5(S D$ 9.2) years and 25 relatives with a mean age of $48.8(S D$ 8.8) years were recruited to the study. Mean time since injury in the patient group was 1.9 years ( $S D$ 2.0). The group programme consisted of 15 weekly sessions of 2.5 hours and included cognitive strategy training, social skills training, and psycho-education. Patients also received homework. Relatives were invited to attend twice. Repeated measurements were taken: prior to treatment (baseline, T0); directly after treatment (T1, 21 weeks); and at follow-up (T2, 45 weeks). Primary outcome measures were individualised goals (GAS), cognitive failures (CFQ), and quality of life (SA-SIP). Patients did improve significantly on individual goals $(p<.05)$ between T0 and T1 and the level of attainment remained stable between T1 and T2. Goals were mostly set in the cognitive and behavioural domains. There were no significant differences between the measurements $(\mathrm{T} 0-\mathrm{T} 1-\mathrm{T} 2)$ on the

Correspondence should be sent to Dr. S. Rasquin, PO Box 88, 6430 AB Hoensbroek, The Netherlands. E-mail: s.rasquin@adelante-zorggroep.nl

(C) 2010 Psychology Press, an imprint of the Taylor \& Francis Group, an Informa business http://www.psypress.com/neurorehab DOI:10.1080/09602011.2010.484645 
CFQ and the SA-SIP. The programme had a positive effect on the individual goals set by the patients. However, this did not result in a higher participation level or a better quality of life. This may be due to the low intensity and short duration of the programme.

Keywords: Brain injury; Cognitive rehabilitation; Outpatient; Chronic; Goal attainment.

\section{INTRODUCTION}

Neuropsychological disorders are common after acquired brain injury (ABI). Cognitive, emotional and behavioural deficits fall within the scope of neuropsychological disorders and are highly prevalent after brain injury (Frencham, Fox, \& Maybery, 2005; Naalt van der, 2001; Rapoport \& Feinstein, 2000; Turner-Stokes \& Hassan, 2002). For a substantial proportion of patients, return to work becomes only partially possible, or absolutely impossible (Drake, Gray, Yoder, Pramuka, \& Llewellyn, 2000; Franulic, Carbonell, Pinto, \& Sepulveda, 2004); the same is applicable to leisure activities (Dikmen, Machamer, Powell, \& Temkin, 2003). Personality changes often account for family disruption (Wyller et al., 2003).

Few patients are well prepared to manage the challenges of daily life and social reintegration after their brain injury. Most patients with acquired brain injury (ABI) who do not experience obvious physical consequences are not screened for cognitive and emotional deficits. Yet, even patients who are discharged to their home environment directly after hospital discharge or after neurorehabilitation without follow-up visits, experience a range of psychosocial consequences in daily life that affect adjustment, long-term recovery and quality of life (Tiersky et al., 2005). Most of these problems become obvious when patients have to return to pre-injury daily routines and try to live an independent life within the full scope of societal participation (Visser-Meily, van Heugten, Schepers, \& van den Bos, 2007). These patients run the risk of burnout, depression or social isolation. To prevent secondary problems, these patients need practical individualised strategies to compensate for cognitive deficits and to learn specific social skills to help them manage their daily life and enhance self-efficacy. Although restoration of function can occur even several years post-injury, teaching compensatory strategies is nowadays considered standard treatment that is effective long after the brain injury occurred (Wilson, 2000; Wilson, Evans, \& Keohane, 2002).

Despite a wide array of research on neuropsychological issues concerning adults with brain injury, few programmes exist that address the long-term needs of brain injury survivors once they are discharged from post-acute programmes (Fraas, Balz, \& Degrauw, 2007; McAllister, 1997). Most cognitive 
rehabilitation programmes are offered to patients in the relatively early phase of recovery from brain damage and are specifically designed to address only one cognitive disorder, such as attention or memory (Carney et al., 1999; Cicerone et al., 2005). In contrast, in comprehensive (holistic) cognitive rehabilitation programmes, which may be residential and offered in the post-acute phase after injury, all aspects of cognitive and emotional consequences after brain injury are incorporated. These programmes are intensive (lasting from weeks to months, mostly four to five days a week) and seem to be effective (Chua, Ng, Yap, \& Bok, 2007; Cicerone, Mott, Azulay, \& Friel, 2004; Malec, 2001; Ponsford, Olver, Ponsford, \& Nelms, 2003; Prigatano, 1999; Salazar et al., 2000). However, these programmes are costly and for some patients both kinds of programmes are rather too specific or too intensive for the problems they encounter.

Until now there have been few treatment possibilities for patients who function independently in daily life in the chronic phase post-injury, but still encounter some problems. Some studies included patients with mild deficits and found that psychotherapy and cognitive remediation had an effect on reduction of emotional distress. However, these treatments were mostly focused on coping with the emotional consequences of brain injury (Tiersky et al., 2005). Other studies found that psycho-education to inform patients with mild brain injury about the consequences is effective (Dittmar, 1997; Miller \& Mittenberg, 1998; Mittenberg, Tremont, Zielinski, Fichera, \& Rayls, 1996; Paniak, Toller-Lobe, Reynolds, Melnyk, \& Nagy, 2000). So it is still unclear what kind of treatment is the best.

In this study we evaluate the effectiveness of an outpatient cognitive rehabilitation programme, offered in the chronic phase post-injury. The purpose of this programme is five-fold: (1) to help patients and caregivers to gain insight into the consequences of the brain damage; (2) to offer strategies to handle cognitive deficits in their daily lives; (3) to learn social skills in order to live with the consequences; (4) to learn how to control emotional reactions; and (5) to enhance self-efficacy. In the present study the effectiveness of the programme is determined for both the patients and their relatives directly after treatment and in the long-term. We hypothesised that patients reached their predefined goals, and subsequently experience fewer cognitive failures and a higher quality of life.

\section{METHODS}

\section{Study design}

A prospective cohort study was conducted with repeated measurements, i.e., before the start of the outpatient cognitive rehabilitation programme 
(T0: baseline); directly after treatment (T1: 21 weeks); and 6 months after treatment (T2: 45 weeks).

\section{Participants}

All patients who had been referred to the outpatient cognitive rehabilitation programme between September 2006 and December 2007 and who met the inclusion criteria for participation in the programme were included in the research study. Patients with brain injury were referred to the treatment programme by neurologists, general practitioners and rehabilitation physicians. Patients were selected for the programme by means of an interview with a psychologist and a rehabilitation physician. In this interview the rehabilitation physician focused on physical functioning and functioning in daily life. The psychologist interviewed the patients with regard to their cognitive and emotional problems. Both the rehabilitation physician and the psychologist assessed the cause of the problems described by the patients (if the cause was different from acquired brain injury, patients were excluded). They also both asked the patients what kind of goals and expectations they had by following the programme (if these purposes were beyond the scope of the programme patients were excluded).

Inclusion criteria patients. The criteria for referral to the treatment programme were the following: patients had sustained an ABI at least three months earlier; patients were older than 18 years; patients experienced cognitive, emotional, and/or behavioural problems that interfered with daily functioning and for which information, advice and treatment were necessary to assure adaptation to these problems; patients had sufficient insight into their individual problems in order to benefit from a low-frequency treatment intensity; communication in daily life was not hindered (patients could read and write); patients' social behaviour was adequate enough for them to function in a group programme; there were currently no treatment goals in the sensori-motor area of functioning (assessed by the rehabilitation physician).

Exclusion criteria patients. Patients with primary psychological or psychiatric disorders, dementia, or a whiplash trauma were excluded from the programme (assessed by the psychologist). The fact that a patient had previously undergone (cognitive) rehabilitation was not an exclusion criterion, as mostly these earlier interventions were focused on specific cognitive deficits.

Inclusion criteria relatives. Inclusion criteria for participation in the research study for relatives (the informal caregivers) of patients referred to the treatment programme were: age older than 18 years, sufficient knowledge of the Dutch language in order to read and understand the questionnaires, and 
informed consent. Caregivers were excluded if they had a brain injury or primary psychiatric disorders.

During the study period, five groups of patients were treated. Thirty-two patients in total received treatment and five patients refused participation in the study. Reasons for decline were fatigue or lack of time of patient or caregiver. Thus 27 patients participated in the study. Table 1 shows the patient characteristics.

Most participants were middle-aged, while more than half the patients had a low level of education. Most frequent cause of brain injury was stroke, followed by traumatic brain injury. Mean time since injury was almost 2 years. In both groups (patients and caregivers) the distribution of males versus females was equal and the caregivers had the same mean age as the patients.

Neuropsychological functioning is presented in Table 2 (for description of tests, see measurements). Deficits were found in all cognitive domains except language, albeit rather mildly. Most deficits were found in the field of attention and memory, followed by executive functioning. Although aphasia was not an exclusion criterion for participation in the programme, none of the patients have language deficits.

\section{Intervention}

The aims of the outpatient cognitive rehabilitation programme are described in the introduction. With these aims, the impairments as such are not treated,

TABLE 1

Patient characteristics

\begin{tabular}{lcc}
\hline & Patient & Caregiver \\
\hline Men - Women $N(\%)$ & $14(52)-13(48)$ & $13(52)-12(48)$ \\
Age at assessment (mean, $S D$, Range) & $49.5(9.2) 29-65$ & $48.8(8.8) 27-68$ \\
Time since injury in years (mean, SD, Range) & $1.9(2.0) 0.4-7.4$ & \\
Education, low-high $N(\%)$ & $16(59)-11(41)$ & \\
Cause of injury $N(\%)$ & & \\
Stroke & $9(33)$ \\
TBI & $5(18)$ \\
SAH & $3(11)$ \\
Brain tumour & $4(14)$ \\
Epilepsy & $1(4)$ \\
Viral infection & $1(4)$ \\
Sinus thrombosis & $1(4)$ \\
HBI & $1(4)$ \\
CTE & $1(4)$ \\
Mixed type & $1(4)$ \\
\hline
\end{tabular}

TBI: traumatic brain injury; SAH: subarachnoid haemorrhage; HBI: hypoxic brain injury; CTE: chronic toxic encephalopathy. 
TABLE 2

Neuropsychological functioning, including number of patients with a deficit

\begin{tabular}{lccc}
\hline & Mean (SD) & Range & N deficit \\
\hline Immediate verbal recall & & & 2 \\
WAIS III Digit Span & $13.8(3.9)$ & $8.0-22.0$ & \\
Episodic memory & & & 7 \\
AVLT & $43.5(9.8)$ & $22.0-63.0$ & 11 \\
RCFT (delayed recall) & $16.8(6.2)$ & $6.0-27.0$ & \\
Attention & & & 11 \\
D2 & $336.2(94.5)$ & $154.0-507.0$ & 7 \\
TMT A & $43.4(24.6)$ & $22.0-150.0$ & 11 \\
TMT B & $92.7(51.0)$ & $40.0-279.0$ & 7 \\
Executive functioning & & & 11 \\
Stroop & $116.3(59.0)$ & $63.0-357.0$ & 6 \\
Phonetic Fluency & $29.8(8.2)$ & $15.0-57.0$ & 5 \\
Semantic Fluency & $22.0(5.2)$ & $12.0-35.0$ & 5 \\
BADS & & & 4 \\
$\quad$ Action Plan & $4.5(1.1)$ & $0.0-5.0$ & \\
Zoo Map & $9.6(3.7)$ & $0.0-7.0$ & 0 \\
Rule Shift & $1.5(2.1)$ & $2.0-6.0$ & \\
Six Elements & $5.1(1.5)$ & & 9 \\
Language & & & \\
AAT & $115.4(3.2)$ & $5.0-25.0$ & \\
Abstract reasoning & $17.1(5.7)$ & & \\
WAIS III Matrices & & & \\
\hline
\end{tabular}

WAIS III: Wechsler Adult Intelligence Test; AVLT: Auditory Verbal Learning Test; RCFT: Rey Complex Figure Test; TMT: Trail Making Test, part A and B; BADS: Behavioural Assessment of the Dysexecutive Syndrome; AAT: Aachen Aphasia Test.

but the patients and their caregivers learn to live with, manage, compensate for and accept these consequences in order to maximise participation in society.

The treatment programme was offered as a group intervention, with a maximum of seven participants per group. Two cognitive therapists conducted the group sessions. The programme consisted of 15 weekly sessions of 2.5 hours, including a half-an-hour coffee break. The first hour of each session consisted of cognitive training aimed at teaching patients strategies for attention, memory and problem solving. Each patient formulated individual strategies. For each cognitive domain, specific exercises were used in which the individual problems of the participants were taken into account. For example, for memory, patients watched the daily news and afterwards they were asked questions about the content of the news. Based on these exercises, patients formulated their own shortcomings (e.g., being interrupted by 
own thoughts, problems with remembering specific topics, long-term memory problems). These shortcomings were then translated into individual strategies, which were discussed in the group sessions; this way also other patients could benefit from it. The second hour of each session consisted of social skills training. In this section the patients learnt how to ask for help, or how to describe the problems encountered due to brain damage. The social skills training was based on role-playing: the therapist played the role of, for instance, an annoying family member. The patients tried to explain to this "family member" why he was not able, for example, to stay at a party until the end. Patients learnt to become more assertive, without being too intrusive. In addition, during all sessions acceptance of the consequences and social support were discussed. Each week patients needed to perform homework. In this homework patients practised the new strategies, sometimes only in one pre-described situation, depending on the capacities of the patients. During the programme a relative of the patient was invited to attend, and psycho-education was the main content of these sessions. In addition, the patients had two individual sessions with a psychologist (apart from the intake procedure). Six weeks after the 15 sessions, a last session was organised in which the patients discussed with each other what they had achieved.

\section{Measurements}

\section{Neuropsychological functioning}

The cognitive status of participants was assessed prior to treatment with well-accepted and validated neuropsychological tests for which norms were available (T0). The purpose of the neuropsychological testing was to get information about the cognitive capacities of the patient. Moreover it also gave information about the level of awareness of the patients. The purpose of the neuropsychological test was not to evaluate the programme, as the programme focused not on the recovery of cognitive impairments as such.

Immediate verbal recall was measured with the Digit Span and Reverse Digit Span of the Wechsler Adult Intelligence scale III (WAIS-III; Wechsler, 1997). Episodic memory was tested with the Auditory Verbal Learning Test (AVLT), immediate and delayed recall (Rey, 1958), and the Complex Figure Test (CFT; immediate and delayed recall) (Osterrieth, 1944; Rey, 1941). Attention was measured with the D2 (Brickenkamp, 1962; Brickenkamp \& Zillmer, 1998), part A of the Trail Making Test (TMT; Reitan, 1956), and card 1 of the Stroop Colour Word Test (SCWT; Stroop, 1935). Executive functions were measured with card 3 of the SCWT, the action plan test, the rule shift test, the zoo map test and the six element test of the Behavioural Assessment of Dysexecutive Syndrome (BADS; Wilson, Alderman, 
Burgess, Emslie, \& Evans, 1996), and part B of the TMT. Language was assessed with the naming part of the Aachen Aphasia Test (AAT; Graetz, De Bleser, \& Willmes, 1992), verbal phonemic fluency with the digits "D", "A" and "T" (verbal semantic fluency of the Groninger Intelligence Test (GIT; Luteijn \& van der Ploeg, 1983) (animals). General intellectual functioning was assessed with the matrices reasoning of the WAIS-III (Wechsler, 1997). A cognitive domain was impaired if one or more scores of the neuropsychological tests for that domain were below cut-off (standard deviation $\geq 2$ or percentile $\leq 5$ or decile $<2$ ). Evaluation of these programmes should not be focused on cognitive deficits (Wilson et al., 2002; Ylvisaker, Hanks, \& Johnson-Greene, 2002). In this study, we did not re-assess neuropsychological tests since we did not expect scores on these tests to change significantly due to a treatment effect.

\section{Primary outcome measures for patients}

Goal Attainment Scaling (GAS). GAS is a global outcome measure for setting individualised goals and assessing the level of attainment of the goals (Kiresuk \& Sherman, 1968). GAS allows for both individualisation of patient goals according to the needs of each patient, and standardisation of measurement by using a summary formula that calculates the extent to which patients' goals are met (Joyce, Rockwood, \& Mate-Kole, 1994). GAS reflects actual improvement in a patients' functional ability (Fisher, 2008). The hypothetical mean GAS score at follow-up is $50(S D=10)$; consistently high or low follow-up scores indicate that goals were too easy (scores $>50$ ), or too difficult to attain (scores $<50$ ) (Gordon, Powell, \& Rockwood, 1999). A GAS score at follow-up of 50 indicates that all predefined goals met the expected outcome at follow-up. At baseline (one week before the start of the programme), a clinical researcher who was not involved in the cognitive rehabilitation programme, but who was familiar with the content of the programme, constructed Goal Attainment Scaling follow-up guides for all patients, either at home or at the rehabilitation centre. The team members of the programme received a copy of the goals so they knew what goals were set by each patient. During the intervention, the goals were not integrated into the treatment sessions. The time point that was set as the target for goal attainment was one week after the end of the programme. At six months follow up, the level of attainment was measured again to see if patients remained at the same level as was attained one week after the end of the programme. If the caregiver was present during the goal-setting procedure and the caregiver was influencing the patient, the clinical researcher made it clear that the patient determined whether the goal was important or not. The clinical researcher scored the short-term level of attainment on the Goal Attainment Scaling follow-up guide with 
the patient one week after the end of the programme. Due to practical reasons, the scoring of the level of attainment was done by phone. The researcher read out loud the descriptions for each level of attainment and asked the patient which description was applicable at the time of measurement. If goals were set together with the caregiver or when the patient was not sure about his or her level of attainment, the caregiver was asked to report the level of attainment. At six months follow up, the clinical researcher made a second phone call to score the level of attainment again. Table 3 shows examples of specific goals set during the intervention. The scope of the goals was in the cognitive, behavioural, emotional and "other" domain. More information about the GAS method can be found in Bouwens, van Heugten, and Verhey (2009). GAS was administered to 22 participants, because the final treatment group did not participate in this measurement due to practical issues.

Cognitive Failure Questionnaire (CFQ). In this self-report questionnaire patients rate the amount of mistakes they make daily due to cognitive deficits, such as forgetting names, or problems with attending to objects or persons. The questionnaire consists of 25 items; patients can rate the frequency of their mistakes on a 5-point scale ("never" to "very often") (Broadbent, Cooper, FitzGerald, \& Parkes, 1982). The range of scoring is 0 to 100 (a higher score denotes more everyday cognitive failures). Ponds, van Boxtel,

TABLE 3

An example of goals set for the intervention

\begin{tabular}{|c|c|c|c|}
\hline & \multicolumn{3}{|c|}{ Goal Areas } \\
\hline & $\begin{array}{c}\text { Dealing with impaired } \\
\text { memory }\end{array}$ & $\begin{array}{c}\text { Acceptance of } \\
\text { consequences injury }\end{array}$ & Coping with aggression \\
\hline $\begin{array}{l}\text { Much less than } \\
\text { expected }(-2)\end{array}$ & $\begin{array}{l}\text { Poor short-term } \\
\text { memory, no use of } \\
\text { memory aids }\end{array}$ & $\begin{array}{l}{ }^{*} \text { No acceptance of } \\
\text { disease }\end{array}$ & $\begin{array}{l}\text { Becomes aggressive in all } \\
\text { situations of } \\
\text { misunderstanding }\end{array}$ \\
\hline $\begin{array}{l}\text { Somewhat less than } \\
\text { expected }(-1)\end{array}$ & $\begin{array}{l}{ }^{*} \text { Uses memory aids } \\
\text { when another person } \\
\text { cues to do so }\end{array}$ & $\begin{array}{l}\text { Received information } \\
\text { on coping strategies, } \\
\text { but no feeling of coping }\end{array}$ & $\begin{array}{l}{ }^{*} \text { Becomes aggressive in } \\
\text { almost all situations of } \\
\text { misunderstanding }\end{array}$ \\
\hline Programme goal (0) & $\begin{array}{l}{ }^{* *} \text { Able to use memory } \\
\text { aids with external cue } \\
\text { like watch }\end{array}$ & $\begin{array}{l}{ }^{* *} \text { Learned how to cope } \\
\text { with disease, but no full } \\
\text { acceptance }\end{array}$ & $\begin{array}{l}\text { Learned how to stay calm, } \\
\text { but does not succeed in all } \\
\text { situations }\end{array}$ \\
\hline $\begin{array}{l}\text { Somewhat better than } \\
\text { expected }(+1)\end{array}$ & $\begin{array}{l}\text { Able to use memory } \\
\text { aids spontaneously }\end{array}$ & Almost full acceptance & $\begin{array}{l}* * \text { Rarely becomes } \\
\text { aggressive }\end{array}$ \\
\hline $\begin{array}{l}\text { Much better than } \\
\text { expected }(+2)\end{array}$ & $\begin{array}{l}\text { No need for memory } \\
\text { aids }\end{array}$ & $\begin{array}{l}100 \% \text { acceptance of } \\
\text { disease }\end{array}$ & $\begin{array}{l}\text { Never becomes } \\
\text { aggressive any more }\end{array}$ \\
\hline
\end{tabular}

*Admission level; **Discharge/follow up level. From Bouwens et al. (2009). 
\& Jolles (2006) extended the CFQ with four items: "higher frequency of", "more hinder of", "more worrying about", and "more irritated about". These extensions were also used in the current study.

Stroke Adapted Sickness Impact Profile (SA-SIP). The SA-SIP is a selfreport questionnaire, which assesses quality of life. The Stroke Adapted version is shorter than the original version, only 30 of the original 136 items are included. Scores range from 0 to100 (higher score denotes worse functioning or lower quality of life). The scale is divided in two subscales: physical and psychosocial functioning. The reliability and validity of the adapted SA-SIP are good (van Straten et al., 1997).

\section{Secondary outcome measures for patients and caregivers}

Next to the primary outcome measures, the following secondary measures were used: Frenchay Activities Index (FAI; Schuling, de Haan, Limburg, \& Groenier, 1993), Symptom Checklist 90 items (SCL-90; Arrindell \& Ettema, 2003), Community Integration Questionnaire (CIQ; McColl, Davies, Carlson, Johnston, \& Minnes, 2001), and the Fatigue Severity Scale (FSS; Krupp, LaRocca, Muir-Nash, \& Steinberg, 1989). For the caregivers the Informant Questionnaire on Cognitive Decline (IQCODE; Jorm \& Jacomb, 1989), Utrechtse Coping List (UCL; Schreurs, 1993), and Caregiver strain index (CSI; Robinson, 1983) were used.

\section{Procedure}

After referral to the treatment programme, patients and relatives were asked to participate in the study. After informed consent was obtained, baseline measurements concerning neuropsychological functioning were conducted in the rehabilitation centre prior to the start of the treatment. Demographic variables as well as medically relevant data (diagnosis, severity of injury, side of injury) were collected from the medical files. Education was divided into high (i.e., primary school + secondary school + higher education) versus low (i.e., primary school and/or secondary vocational education).

The questionnaires for patients as well as relatives were sent to their home addresses and they were asked to fill in the questionnaires themselves, independently of each other. During a home visit by a member of the research team the questionnaires were checked to see if they were complete. In addition, the goals for the GAS procedure were set together with the patient. This procedure was conducted prior to the treatment (T0). In the week immediately after the treatment (T1: 21 weeks later) and 6 months after the end of the treatment (T2: in total 45 weeks after the start of treatment) the questionnaires were sent by mail and a member of the research 
team called the participants to score the level of attainment per goal by phone. The Ethics Committee approved the study protocol.

\section{Statistical analyses}

Descriptive statistics were used to describe the demographic variables, neuropsychological functioning and daily functioning. Primary outcome measures of this study are the GAS, CFQ and SA-SIP. Pre- and post-assessment were compared to each other (T0-T1, T1-T2, and T0-T2). For these analyses, a repeated measures ANOVA (General linear model with repeated measures, GLM) was conducted with the outcome scores on all primary outcome measures as within-subject variables and the time of measurement (T0, T1 and T2) as between subject variables in order to investigate the effect of treatment. Tukey post hoc tests were requested to evaluate whether differences in mean outcome scores for the different times of measurement were significant. Statistical analyses were performed with the Statistical Package for Social Sciences (version 16.0) with an alpha level set at .05 for all analyses.

\section{RESULTS}

\section{Effect of the programme measured with GAS}

GLM shows an effect of time on the GAS scores $(p<.05)$. A significant mean difference on the GAS scores exists between T0 and T1 and T0 and $\mathrm{T} 2(F=94.705, p<.05)$. The effect size was 4.7. No significant differences were found on the GAS scores between T1 and T2 $(p>.05)$. Figure 1 shows the GAS scores for all participants over time.

Table 4 gives an overview of the distribution of the number of goals set in the general and specific domains. In total 93 goals were set. The mean $(S D)$ number of goals was 4.2 (1.1) per participant (range 2-6). Most goals were set in the cognitive domain (e.g., memory and attention), followed by the behavioural domain (e.g., take some rest and fatigue).

\section{Short-term effects of the programme}

Table 5 presents the results of the primary outcome measures. No significant differences were found between baseline (T0) and directly after the end of the programme (T1) on these outcome measures (SASIP total: $F=0.08$, $p>.05$; SASIP physical: $1.45, p>.05$; SASIP psychosocial: $F=0.42$, $p>.05$; CFQ: $F=0.46, p>.05)$. 


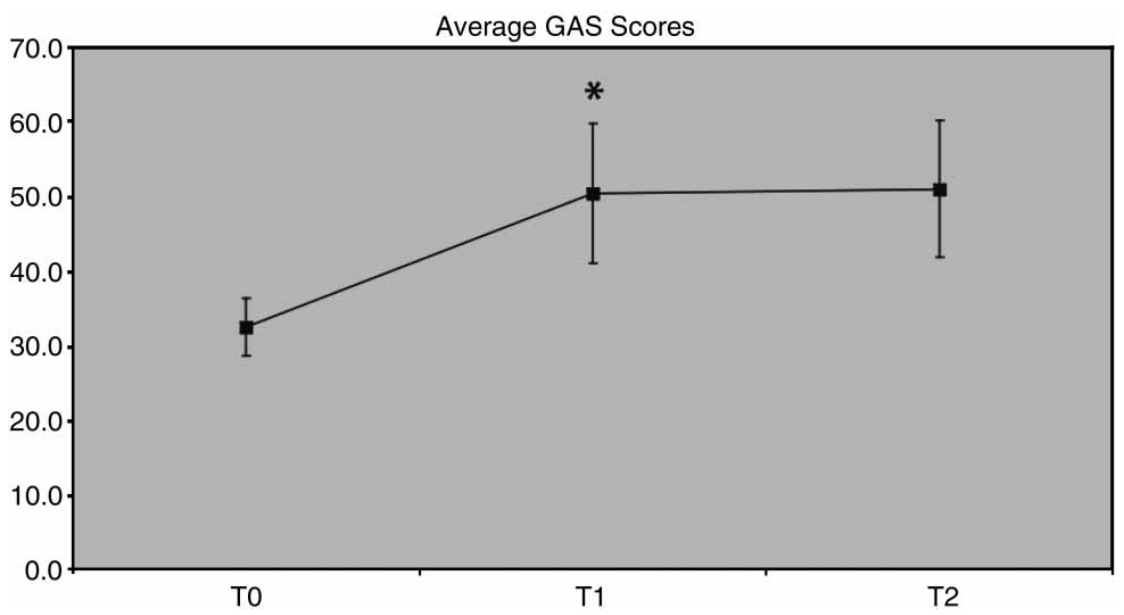

Figure 1. Change of GAS scores over time.

\section{Long-term effects of the programme}

We explored the differences between the measurements directly after the programme (T1) and 6 months after the end of the treatment (T2). There were no significant changes on the primary outcome measures SA-SIP and CFQ. The only significant change between $\mathrm{T} 1$ and $\mathrm{T} 2$ was found for the secondary outcome measure FAI $(F=7.04)$. The mean scores of this scale increased between T0 and T1 $(p=.01)$, indicating better functioning on IADL and social activities. The FAI was also the only outcome measure that changed between T0 and T2 $(p=.02)$. Again the mean scores of this scale increased, indicating better functioning on IADL and social activities.

TABLE 4

Domains in which goals were set with GAS

\begin{tabular}{|c|c|c|c|c|c|c|c|}
\hline Cognition & $N$ & Emotion & $N$ & Behaviour & $N$ & Other & $N$ \\
\hline Memory & 14 & Self-esteem & 1 & $\begin{array}{r}\text { Impulsivity/ } \\
\text { inhibition }\end{array}$ & 3 & Work-related & 1 \\
\hline Attention/concentration & 12 & Fear & 4 & Aggression/temper & 5 & Education & 4 \\
\hline Planning/organising & 5 & Acceptance & 8 & Social skills & 5 & Peer support & \\
\hline Structure & 1 & Mood & 1 & Fatigue & 5 & Physical & 1 \\
\hline Strategy use & 6 & Burden & 2 & Take some rest & 7 & Administration & 1 \\
\hline Double tasking & 1 & & & Restless & 4 & & \\
\hline Flexibility & 2 & & & & & & \\
\hline Total & 41 & & 16 & & 29 & & 7 \\
\hline
\end{tabular}


TABLE 5

Mean scores on the primary outcome measures and differences between the assessments

\begin{tabular}{lcccccc}
\hline Questionnaire & $\begin{array}{c}\text { To Mean } \\
(S D)\end{array}$ & $\begin{array}{c}\text { T1 Mean } \\
(S D)\end{array}$ & $\begin{array}{c}\text { T2 Mean } \\
(S D)\end{array}$ & $\begin{array}{c}\text { T0-T1 } \\
\text {-value } \\
(N)\end{array}$ & $\begin{array}{c}\text { T1-T2 } \\
p \text {-value } \\
(N)\end{array}$ & $\begin{array}{c}\text { T0-T2 } \\
p \text {-value } \\
(N)\end{array}$ \\
\hline Patient & & & & & & \\
SA-SIP Total & $24.9(11.5)$ & $24.5(15.2)$ & $23.9(15.1)$ & $1.00(23)$ & $1.00(23)$ & $1.00(23)$ \\
SA-SIP Physical & $8.8(10.5)$ & $12.6(13.9)$ & $9.9(14.7)$ & $0.18(23)$ & $0.92(23)$ & $1.00(23)$ \\
SA-SIP Psychosocial & $41.0(18.2)$ & $36.7(23.1)$ & $39.1(22.9)$ & $1.00(23)$ & $1.00(23)$ & $1.00(23)$ \\
CFQ & $48.8(15.6)$ & $49.3(17.1)$ & $49.4(16.7)$ & $1.00(23)$ & $1.00(23)$ & $1.00(23)$ \\
\hline
\end{tabular}

${ }^{*} p<.05$; SA-SIP: Stroke Adapted Sickness Impact Profile; CFQ: Cognitive Failure Questionnaire; T0-T1: Effect from before to directly after programme; T1-T2: Effect from directly after programme to 6 months later.

We also looked at individual changes on the other questionnaires. These were random: some patients improved on some questionnaires, whereas others deteriorated or did not change, there was no consistency and there were no statistical differences.

\section{DISCUSSION}

This is the first prospective report showing the effect of a low intensity and short duration outpatient cognitive rehabilitation programme on a group of patients with $\mathrm{ABI}$ with subtle cognitive as well as emotional and social consequences in the chronic phase post-injury. We found that patients attained their pre-defined goals. This finding remained stable six months after the end of the programme. We did not find evidence for fewer cognitive failures or improved quality of life as measured with the CFQ and SA-SIP, respectively. It is remarkable that most goals were attained in the cognitive domain, while cognitive failures did not improve significantly. The level of social activities (as measured with the FAI) did significantly increase after treatment. Moreover, none of the other secondary measures for patients and caregivers showed significant changes either in the short or the long term. It seems that, although patients attain their individual goals, this does not result in a higher participation level or a better quality of life. Other studies did find improvement in the quality of life, participation or employability (Geurtsen, Martina, Van Heugten, \& Geurts, 2008; Sarajuuri et al., 2005; Tiersky et al., 2005). However, the intensity of these programmes was much higher compared to ours. This could be a possible explanation for the lack of positive findings.

An alternative explanation is that GAS focuses on what the participants want to attain themselves and this is probably of more importance than the 
domains covered by the other outcome measures used for this study. In other words, GAS is patient-based while the other measures were probably more intervention-based. The goal of the intervention is to improve daily life by focusing on coping with daily life problems. GAS turned out to be the most sensitive instrument with which to measure outcome of the intervention. In addition, improvement in daily life is also shown by the FAI. Liu et al. (2004) state that goal attainment is seldom reported in studies of rehabilitation effectiveness. While GAS has the advantage of individual flexibility and sensitivity to treatment, it has been criticised as being overly subjective (Boothroyd, Banks, Evans, Greenbaum, \& Brown, 2004). In addition, during the measurement at the end of treatment, all patients reported that they were very content about the treatment programme as it gave them the opportunity to talk about and share their experiences. Peer support programmes have indeed been found to be a promising way to approach the enhancement of patients' and families' ability to cope (Hibbard et al., 2002).

Focusing on what the patients want themselves, is also probably close to what is actually trained during the programme. In other words, the lack of effect on cognitive failures and quality of life might also be a reflection of a lack of generalisation effects. As we have shown in earlier studies on the effects of cognitive rehabilitation, generalisation does not occur spontaneously and should be discussed explicitly (Geusgens, Winkens, van Heugten, Jolles, \& van den Heuvel, 2007), which is not done during this programme.

Although executing a follow up GAS by phone has some disadvantages, such as the impossibility of seeing non-verbal cues, an advantage of the use of the phone is that it is time effective. As described in Bouwens et al. (2009), our experience was that the patients understood the goal setting procedure and were able to report their level of functioning during a phone call. Furthermore, the nature of most goals set did not allow direct observation (e.g., level of acceptance). Therefore, it was not necessary to actually see the patients. By formulating the levels of attainment in a clear manner at baseline, it was possible for the researcher to assess level of attainment by phone. When goals have an observable nature, such as number of metres that a person can walk after an intervention, it is not possible to do the follow up assessment by phone. We did not expect patients to show deterioration on some of the questionnaires. However, we know from other studies that a response shift could have occurred, in which patients become more aware of their problems due to the programme (Beutler, Moos, \& Lane, 2003). We did not find that any particular group of patients deteriorated or improved. Changes in answers on questionnaires were random; some patients showed improvement on some questionnaires, but deterioration on others.

The results found should be interpreted against the shortcomings of the study. The design of this study is a pre-post test design, with a follow-up assessment. This was an open trial in order to examine the effectiveness of a new cognitive 
rehabilitation programme. This design provides an initial insight into the effects of this type of programme for patients with acquired brain injury.

In conclusion, our results indicate that patients profit from the education, cognitive strategies and social skills learned in this outpatient cognitive rehabilitation programme. The effects are mostly observed in individually defined goals. Improvements in the domains of participation and quality of life are probably only reached when the intensity of the programme is increased or generalisation is encouraged explicitly. This should however be confirmed in future studies.

\section{REFERENCES}

Arrindell, W. A., \& Ettema, J. H. M. (2003). Symptom Checklist [Handleiding bij een multidimensionele psychopathologie-indicator]. Lisse: Swets \& Zeitlinger B.V.

Beutler, L., Moos, R., \& Lane, G. (2003). Coping, treatment planning, and treatment outcome: Discussion. Journal of Clinical Psychology, 59, 1151-1157.

Boothroyd, R. A., Banks, S. M., Evans, M. E., Greenbaum, P. E., \& Brown, E. (2004). Untangling the web: An approach to analyzing the impacts of individually tailored, multicomponent treatment interventions. Mental Health Services Research, 6(3), 143-153.

Bouwens, S. F., van Heugten, C. M., \& Verhey, F. R. (2009). The practical use of goal attainment scaling for people with acquired brain injury who receive cognitive rehabilitation. Clinical Rehabilitation, 23(4), 310-320.

Brickenkamp, R. (1962). Aufmerksamkeits-Belastungs-Test (test d2) [The d2 test of attention]. Gottingen: Hogrefe.

Brickenkamp, R., \& Zillmer, E. (1998). The d2 Test of Attention. Seattle, WA: Hogrefe \& Huber Publishers.

Broadbent, D. E., Cooper, P. F., FitzGerald, P., \& Parkes, K. R. (1982). The Cognitive Failures Questionnaire (CFQ) and its correlates. British Journal of Clinical Psychology, 21(Pt 1), 1-16.

Carney, N., Chesnut, R. M., Maynard, H., Mann, N. C., Patterson, P., \& Helfand, M. (1999). Effect of cognitive rehabilitation on outcomes for persons with traumatic brain injury: A systematic review. Journal of Head Trauma Rehabilitation, 14(3), 277-307.

Chua, K. S., Ng, Y. S., Yap, S. G., \& Bok, C. W. (2007). A brief review of traumatic brain injury rehabilitation. Annual Academic Medicine Singapore, 36(1), 31-42.

Cicerone, K. D., Dahlberg, C., Malec, J. F., Langenbahn, D. M., Felicetti, T., Kneipp, S., et al. (2005). Evidence-based cognitive rehabilitation: Updated review of the literature from 1998 through 2002. Archives of Physical Medicine and Rehabilitation, 86(8), 1681-1692.

Cicerone, K. D., Mott, T., Azulay, J., \& Friel, J. C. (2004). Community integration and satisfaction with functioning after intensive cognitive rehabilitation for traumatic brain injury. Archives of Physical Medicine and Rehabilitation, 85(6), 943-950.

Dikmen, S. S., Machamer, J. E., Powell, J. M., \& Temkin, N. R. (2003). Outcome 3 to 5 years after moderate to severe traumatic brain injury. Archives of Physical Medicine and Rehabilitation, 84(10), 1449-1457.

Dittmar, C. (1997). Outpatient rehabilitation program for clients with persisting mild to moderate symptoms following traumatic brain injury. Applied Neuropsychology, 4(1), 50-54.

Drake, A. I., Gray, N., Yoder, S., Pramuka, M., \& Llewellyn, M. (2000). Factors predicting return to work following mild traumatic brain injury: A discriminant analysis. Journal of Head Trauma Rehabilitation, 15(5), 1103-1112. 
Fisher, K. (2008). Assessing clinically meaningful change following a programme for managing chronic pain. Clinical Rehabilitation, 22(3), 252-259.

Fraas, M., Balz, M., \& Degrauw, W. (2007). Meeting the long-term needs of adults with acquired brain injury through community-based programming. Brain Injury, 21(12), $1267-1281$.

Franulic, A., Carbonell, C. G., Pinto, P., \& Sepulveda, I. (2004). Psychosocial adjustment and employment outcome 2, 5 and 10 years after TBI. Brain Injury, 18(2), 119-129.

Frencham, K. A., Fox, A. M., \& Maybery, M. T. (2005). Neuropsychological studies of mild traumatic brain injury: A meta-analytic review of research since 1995. Journal of Clinical and Experimental Neuropsychology, 27(3), 334-351.

Geurtsen, G. J., Martina, J. D., Van Heugten, C. M., \& Geurts, A. C. (2008). A prospective study to evaluate a new residential community reintegration programme for severe chronic brain injury: The Brain Integration Programme. Brain Injury, 22(7), 545-554.

Geusgens, C. A., Winkens, I., van Heugten, C. M., Jolles, J., \& van den Heuvel, W. J. (2007). Occurrence and measurement of transfer in cognitive rehabilitation: A critical review. Journal of Rehabilitation Medicine, 39(6), 425-439.

Gordon, J. E., Powell, C., \& Rockwood, K. (1999). Goal attainment scaling as a measure of clinically important change in nursing-home patients. Age and Ageing, 28(3), 275-281.

Graetz, P., De Bleser, R., \& Willmes, K. (1992). Akense Afasietest, Nederlandse versie. Lisse: Swets \& Zeitlinger.

Hibbard, M. R., Cantor, J., Charatz, H., Rosenthal, R., Ashman, T., Gundersen, N., et al. (2002). Peer support in the community: Initial findings of a mentoring program for individuals with traumatic brain injury and their families. Journal of Head Trauma Rehabilitation, 17(2), $112-131$.

Jorm, A. F., \& Jacomb, P. A. (1989). The Informant Questionnaire on Cognitive Decline in the Elderly (IQCODE): Socio-demographic correlates, reliability, validity and some norms. Psychological Medicine, 19(4), 1015-1022.

Joyce, B. M., Rockwood, K. J., \& Mate-Kole, C. C. (1994). Use of goal attainment scaling in brain injury in a rehabilitation hospital. American Journal of Physical Medicine and Rehabilitation, 73(1), 10-14.

Kiresuk, T., \& Sherman, R. E. (1968). Goal Attainment Scaling: A general method for evaluating comprehensive community mental health programs. Community Mental Health Journal, 4(6), 443-453.

Krupp, L., LaRocca, N., Muir-Nash, J., \& Steinberg, A. (1989). The fatigue severity scale. Application to patients with multiple sclerosis and systemic lupus erythematosus. Archives Neurology, 46(10), 1121-1123.

Liu, C., McNeil, J. E., \& Greenwood, R. (2004). Rehabilitation outcomes after brain injury: Disability measures or goal achievement? Clinical Rehabilitation, 18(4), 398-404.

Luteijn, F., \& van der Ploeg, F. A. E. (1983). Manual Groninger Intelligence Test. Lisse: Swets and Zeitlinger.

Malec, J. F. (2001). Impact of comprehensive day treatment on societal participation for persons with acquired brain injury. Archives of Physical Medicine and Rehabilitation, 82(7), 885-895.

McAllister, T. (1997). Evaluation of brain injury related behavioral disturbances in community mental health centers. Community Mental Health Journal, 33(4), 341-364.

McColl, M. A., Davies, D., Carlson, P., Johnston, J., \& Minnes, P. (2001). The community integration measure: Development and preliminary validation. Archives of Physical Medicine and Rehabilitation, 82(4), 429-434.

Miller, L. J., \& Mittenberg, W. (1998). Brief cognitive behavioral interventions in mild traumatic brain injury. Applied Neuropsychology, 5(4), 172-183. 
Mittenberg, W., Tremont, G., Zielinski, R. E., Fichera, S., \& Rayls, K. R. (1996). Cognitivebehavioral prevention of postconcussion syndrome. Archives of Clinical Neuropsychology, 11(2), 139-145.

Naalt van der, J. (2001). Prediction of outcome in mild to moderate head injury: A review. Journal of Clinical and Experimental Neuropsychology, 23(6), 837-851.

Osterrieth, P. A. (1944). Le test de copie d'une figure complex: Contribution a l'etude de la perception et de la memoire. Archives de Psychologie, 30, 286-356.

Paniak, C., Toller-Lobe, G., Reynolds, S., Melnyk, A., \& Nagy, J. (2000). A randomized trial of two treatments for mild traumatic brain injury: 1 year follow-up. Brain Injury, 14(3), 219-226.

Ponds, R. W., van Boxtel, M., \& Jolles, J. (2006). The Cognitive Failure Questionaire as a measure for subjective functioning. [in Dutch]. Tijdschrift voor Neuropsychologie, 1(2), $37-42$.

Ponsford, J., Olver, J., Ponsford, M., \& Nelms, R. (2003). Long-term adjustment of families following traumatic brain injury where comprehensive rehabilitation has been provided. Brain Injury, 17(6), 453-468.

Prigatano, G. P. (1999). Principles of neuropsychological rehabilitation. Oxford: Oxford University Press.

Rapoport, M. J., \& Feinstein, A. (2000). Outcome following traumatic brain injury in the elderly: A critical review. Brain Injury, 14(8), 749-761.

Reitan, R. (1956). Trail Making Test: Manual for administration, scoring, and interpretation. Bloomington: Indiana University.

Rey, A. (1941). L'examinen psychologique dans les cas d'encephalopathie traumatique. Archives de Psychologie, 28, 286-340.

Rey, A. (1958). L'examen clinique en psychologie [The clinical examination in psychology]. Paris: Presses Universitaires de France.

Robinson, B. C. (1983). Validation of a Caregiver Strain Index. Journal of Gerontology, 38(3), 344-348.

Salazar, A. M., Warden, D. L., Schwab, K., Spector, J., Braverman, S., Walter, J., et al. (2000). Cognitive rehabilitation for traumatic brain injury: A randomized trial. Defense and Veterans Head Injury Program (DVHIP) Study Group. Journal of the American Medical Association, 283(23), 3075-3081.

Sarajuuri, J. M., Kaipio, M. L., Koskinen, S. K., Niemela, M. R., Servo, A. R., \& Vilkki, J. S. (2005). Outcome of a comprehensive neurorehabilitation program for patients with traumatic brain injury. Archives of Physical Medicine and Rehabilitation, 86(12), 2296-2302.

Schreurs, P. J. G. (1993). De Utrechtse Coping Lijst (UCL): omgaan met problemen en gebeurtenissen (Vol. Swets \& Zeitlinger). Utrecht.

Schuling, J., de Haan, R., Limburg, M., \& Groenier, K. H. (1993). The Frenchay Activities Index. Assessment of functional status in stroke patients. Stroke, 24(8), 1173-1177.

Stroop, J. R. (1935). Studies of interference in serial verbal reactions. Journal of Experimental Psychology, 18, 643-662.

Tiersky, L. A., Anselmi, V., Johnston, M. V., Kurtyka, J., Roosen, E., Schwartz, T., et al. (2005). A trial of neuropsychologic rehabilitation in mild-spectrum traumatic brain injury. Archives of Physical Medicine and Rehabilitation, 86(8), 1565-1574.

Turner-Stokes, L., \& Hassan, N. (2002). Depression after stroke: A review of the evidence base to inform the development of an integrated care pathway. Part 1: Diagnosis, frequency and impact. Clinical Rehabilitation, 16(3), 231-247.

van Straten, A., de Haan, R. J., Limburg, M., Schuling, J., Bossuyt, P. M., \& van den Bos, G. A. (1997). A stroke-adapted 30-item version of the Sickness Impact Profile to assess quality of life (SA-SIP30). Stroke, 28(11), 2155-2161. 
Visser-Meily, J., van Heugten, C., Schepers, V., \& van den Bos, G. (2007). There are also suitable treatments during the chronic phase following a stroke. [in Dutch] Nederlands Tijdschrift voor Geneeskunde, 15(151), 2753-2757.

Wechsler, D. (1997). Wechsler Adult Intelligence Scale-III. San Antonio, TX: The Psychological Corporation.

Wilson, B. A. (2000). Compensating for cognitive deficits following brain injury. Neuropsychological Review, 10(4), 233-243.

Wilson, B. A., Alderman, N., Burgess, P. W., Emslie, H., \& Evans, J. J. (1996). Behavioural Assessment of the Dysexecutive Syndrome (BADS). Bury St. Edmunds: Thames Valley Test Company.

Wilson, B. A., Evans, J. J., \& Keohane, C. (2002). Cognitive rehabilitation: A goal-planning approach. Journal of Head Trauma Rehabilitation, 17(6), 542-555.

Wyller, T. B., Thommessen, B., Sodring, K. M., Sveen, U., Pettersen, A. M., Bautz-Holter, E., et al. (2003). Emotional well-being of close relatives to stroke survivors. Clinical Rehabilitation, 17(4), 410-417.

Ylvisaker, M., Hanks, R., \& Johnson-Greene, D. (2002). Perspectives on rehabilitation of individuals with cognitive impairment after brain injury: rationale for reconsideration of theoretical paradigms. Journal of Head Trauma Rehabilitation, 17(3), 191-209.

Manuscript received April 2009

Revised manuscript received March 2010

First published online June 2010 